\title{
Electrical-Thermal-Mechanical Analysis of Cable Connection with Screw-Connected Terminal Strips Using Finite Element Method
}

\author{
Dustafa TOSUN ${ }^{1}$, (DHüseyin AKSOY ${ }^{2}$ \\ ${ }^{1}$ Corresponding Author; Department of Electrical and Electronics Engineering, Simav Technology Faculty, \\ Kutahya Dumlupinar University, Kutahya, Turkey; mustafa.tosun@dpu.edu.tr; +90 5335204006 \\ ${ }^{2}$ Department of Electrical and Electronics Engineering, Simav Technology Faculty, \\ Kutahya Dumlupinar University, Kutahya, Turkey; haksoy43@gmail.com
}

Received 2 July 2020; Revised 21 December 2020; Accepted 25 February 2021; Published online 11 March 2021

\begin{abstract}
Electric energy passes through many stages from production to usage, and many electrical connections take place at these stages. Electrical connections are quite important for system safety and electrical energy quality. In this study, current-temperature relationship in the cable was investigated in cable joints made with screw connection terminals, depending on torque applied to screw. In numerical solution of the problem, Comsol Multiphysics program based on Finite Element Method was used first, the screw-conductor interface was investigated based on applied torque, and then electrical-thermal analysis was performed on this geometry. Experimental studies were carried out to demonstrate accuracy of digital model, and conductors and terminals used in household installations were taken into account in these studies. Amount of deformation of conductors depending on torque applied to screw and its effect to current carrying capacity of these terminals having screw connection were investigated. In this study, the appropriate torque value is $0.4 \mathrm{Nm}$, and the maximum temperature value is $45^{\circ} \mathrm{C}$ on contact surface. Also, it has been shown that the optimum torque value to be applied in the copper conductor cable joint with 1.5 $\mathrm{mm}^{2}$ cross section area is $0.4 \mathrm{Nm}$.
\end{abstract}

Keywords: Connector, COMSOL Multiphysics, Conductor junction, Electrical Analysis, Finite Element Method, Screw-connection terminal strips, Thermal Analysis

\section{Introduction}

Today, development level of countries is measured by energy consumption [1]. Electricity consumption in the world has increased day by day [2]. Cables used in transmission of electricity are connected by different joints methods. Connection elements used in electrical energy transmission systems are very important for these systems [3]. In addition, proper electrical connections are required to ensure both systems safety and transmission of electrical energy with less loss [4]. In studies of building fires occurred in Turkey was determined to be caused by electrical installations of 19\% [5]. In electrical installations, the riskiest parts of cables are cable joint points [6]. Some of faults in cable joints are due to operators. At the beginning of these faults, screw-type joint method involves over-tightening or loosening the screw.

Cable joints are among the most important factors affecting the maximum current carrying value of cables [7]. In order to place transmission lines, which are used especially in high voltage, under ground cable parameters [8] and environmental parameters are determined [9]. In addition, electrical field control was made at connection points and ends of these cables [10,11]. Finite element method is widely used for static electrical field analysis in cable joints [11,12]. Shazly Jehan H. et al. [7] Have used COMSOL Multiphysics software to evaluate three-phase underground cable, steady state and transient thermal performance. Both analytical and numerical methods have been developed in cables to calculate distribution of temperature caused by current. Analytical methods can be applied only in homogeneous ambient conditions and in simple geometries. Therefore, various numerical models have been developed to examine current carrying capacity of cables in various mounting situations $[13,14,28]$. COMSOL is a suite of finite element modeling software with a predefined set of physics interfaces. This software facilitates development of numerical models by solving partial differential equations $[11,15]$. 
Tosun et al.

In this study, electrical-thermal analysis of cable joints made with screw connection terminal blocks produced with COMSOL software for use in 220-volt voltage values in house electrical installations with electrical and thermal-mechanical analysis was performed. In the first phase of the study, different values of torque forces were applied to the screw by the experimental setup. The amount of crushing (deformation) in the conductor due to the applied torque forces was measured. In order to examine effects of deformation of the conductor on current carrying capacity of the conductor, temperature values occurring on conductive surface depending on conductor flow were measured. In the second phase of the study, screw connection terminal model is modeled by using COMSOL multiphysics software. Then, electrical, thermal and mechanical analysis were performed on this model. In the mechanical analysis of the designed model, the screw was tightened with forces determined in specified values and stressdeformation analysis on the conductor surface in this contact area was performed. After contact was formed, current density analysis and potential difference analysis were performed by applying 14 Amperes current to cable joint area for electrical analysis of the model. In the thermal analysis section, temperature changes due to current and contact pressure were analyzed. As a result of the analyzes, the optimum torque value for the copper conductor cable joint with a cross sectional area of $1.5 \mathrm{~mm}^{2}$ was found to be $0.4 \mathrm{Nm}$.

\section{Material and Method}

Insulating parts of terminal blocks are made of plastic, porcelain or bakelite according to the purpose of use. Rice, nickel and steel materials are mostly used in the conductor interior. Screw connection terminals have insulation material, terminal and screw. The insulation material is made of polyethylene (PE) material to prevent contact of conductive surfaces with each other and to prevent short circuit. The tightening torque applied to the screw creates a torsional shear stress on the screw. The torque applied to object is calculated by following Equation 1 [16].

$$
\theta=r F \sin \theta
$$

Here $\theta$; the angle $\mathrm{r}$ between $\mathrm{R}$ and $\mathrm{F}$; The distance of the force from the axis of rotation (m) is $\mathrm{F}$; The applied force $(\mathrm{N})$ is $\theta$, Torque (SI): Nm. When a material is subjected to a tensile load along a single axis, the relationship between stress and strain occurring in the material is determined by Hooke's Law $[17,18]$ which is given in Equation 2.

$$
\text { Coefficient }=\text { Stress } / \text { Strain }
$$

The coefficient constant for normal stress along the $\mathrm{X}$ axis is given in Equation 3 .

$$
\mathrm{E}=\sigma_{\mathrm{x}} / \varepsilon_{\mathrm{x}}
$$

The relationship between tensile stress and axial stress in the linear elastic region of a material is calculated by Equation 3. In the Equation 3, $\varepsilon_{\mathrm{x}}$ expresses proportional deformation while $\sigma_{\mathrm{x}}$ refers to force per unit area. These two ratios allow to obtain Young's modulus (E). [19,20,21]. Conductivity is one of the main characteristics that separates copper from other metals. Pure copper, aluminum and silver are conductive materials commonly used in electricity production. Electrical conductivity of materials is given in Equation 4 [22].

$$
\sigma=\text { n. q. } \mu
$$

Here, $\sigma$ is the electrical conductivity, the amount of load passing through the conductor, the charge quantity q, and the $\mu$ load bearing constant.

\subsection{Experimental Measurement Board}

In the experimental part of this study, the connection between current and temperature in the conductor was investigated depending on the torque applied to the screw in the cable joints using screw connection terminals. For this process, the experimental setup shown in Figure 1 was formed. In this board; torque screwdriver, screw connection terminal block, H07V (NYA) type used in electrical installations, PVC insulated, without sheath, single-core $1,5 \mathrm{~mm}^{2}$ copper conductor cable, arc welding machine with 
transformer as power supply, measuring the temperature in terminals and conductors with current passing through the conductor, one multimeter pliers' ammeter was used.

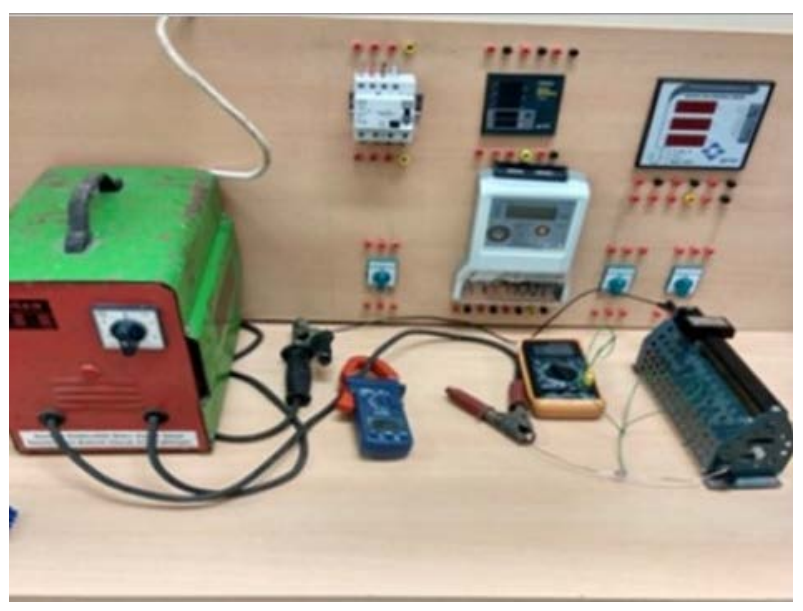

Figure 1 Image of the experiment setup

The screw connection terminal block used was made of special C-45 steel. Insulation part of terminal block was made of Polyamide 6.6 that does not melt until 140 Celsius degrees.

In screw connection terminals, conductor-terminal connection was made with a torque-adjustable screwdriver as shown in Figure 2.

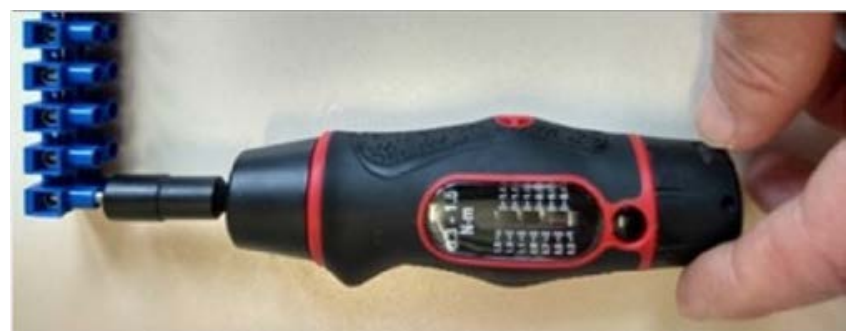

Figure 2 Torque Screwdriver

Torque values of $0.3 \mathrm{Nm}, 0.4 \mathrm{Nm}$ and $0.5 \mathrm{Nm}$ were applied to the screw with a screwdriver. Deformation values of these forces applied on the cable conductor were then measured. Temperature values of cable connections with $1,5 \mathrm{~mm}^{2}$ cross-sectional area were measured by applying a constant current of $14 \mathrm{~A}$ to cable connections formed by applying torque forces mentioned above.

\subsection{Modeling with COMSOL Software}

The finite element method is a method used to solve complex structural physical problems in engineering analysis and design [23,24]. In this method, object to be modeled is divided into small and simple finite elements [25] and mathematical solutions of each element are obtained Figure 3 [26,27]. 


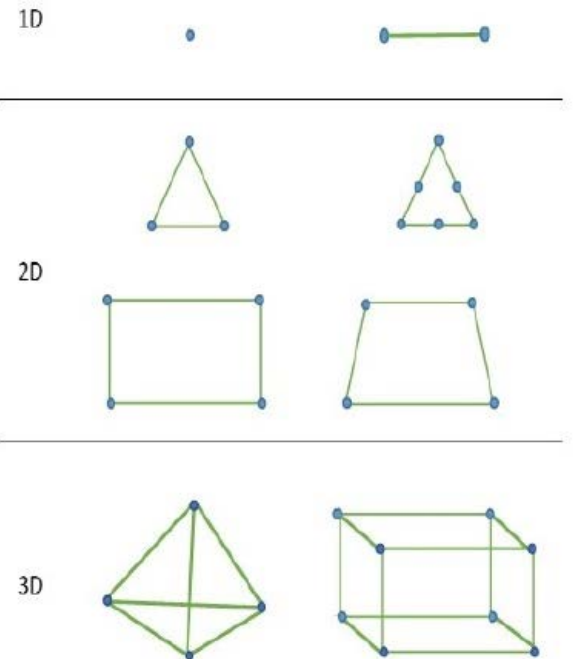

Figure 3 Shapes of elements of basic structure for finite element method [23]

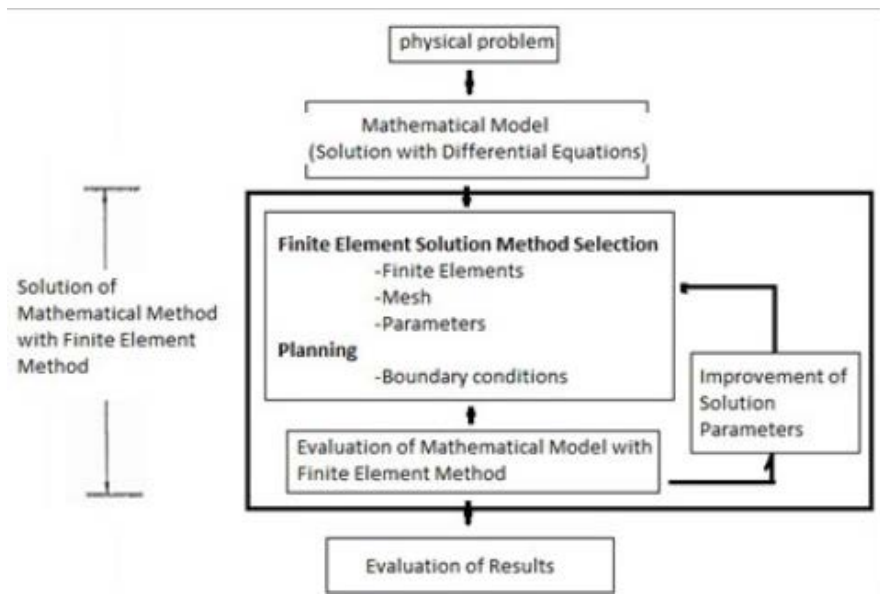

(a)

\begin{tabular}{|c|c|c|c|c|c|}
\hline$"$ & Property & Name & Value & Unit & Property group \\
\hline$\nabla$ & Density & rho & $8960[\mathrm{~kg} / \ldots$ & $\mathrm{kg} / \mathrm{m}^{3}$ & Basic \\
\hline$\nabla$ & Young's modulus & $\mathrm{E}$ & $110 e 9[\mathrm{~Pa}]$ & $\mathrm{Pa}$ & Young's modulus and Pois... \\
\hline \multirow[t]{10}{*}{$\nabla$} & Poisson's ratio & nu & 0.35 & 1 & Young's modulus and Pois... \\
\hline & Relative permeability & mur & 1 & 1 & Basic \\
\hline & Electrical conductivity & sigma & $5.998 \mathrm{e} 7[\ldots$ & $\mathrm{S} / \mathrm{m}$ & Basic \\
\hline & Coefficient of thermal expansion & alpha & $17 \mathrm{e}-6[1 / \mathrm{K}]$ & $1 / K$ & Basic \\
\hline & Heat capacity at constant pressure & $C p$ & $385[\mathrm{~J} /(\mathrm{kg} \ldots$ & $\mathrm{J} /(\mathrm{kg} \cdot \mathrm{K})$ & Basic \\
\hline & Relative permittivity & epsilonr & 1 & 1 & Basic \\
\hline & Thermal conductivity & $\mathrm{k}$ & $400[W /(\ldots$ & $W /(m \cdot K)$ & Basic \\
\hline & Reference resistivity & rhoo & $1.72 \mathrm{e}-8[\ldots$ & $\Omega \cdot m$ & Linearized resistivity \\
\hline & Resistivity temperature coefficient & alpha & $0.0039[1 / \ldots$ & $1 / K$ & Linearized resistivity \\
\hline & Reference temperature & Tref & $298[\mathrm{~K}]$ & K & Linearized resistivity \\
\hline
\end{tabular}

(b)

Figure 4 a) Finite element method process b) Finite element method conditions

Figure 4a shows the finite element analysis process. Physical problems (pre-processes -Modeling):

- $\quad$ Determination of problem type (electric-thermal-mechanical)

- $\quad$ Establishment of mesh structure

- Determination of material properties (hardness, conductivity, heat, Young’s Module etc.).

Mathematical model solution: 
- $\quad$ Apply loads and boundary conditions

- $\quad$ Let computer do numerical calculations

- $\quad$ Restart from pro-processing if error occurs

Improving Solution Parameters:

- $\quad$ Display Results in tables or graphs

- $\quad$ Review if result is reasonable

- If not, restart from pre-processing

Electrical analysis modeling equations are based on Maxwell's equations. AC/DC interfaces formulate the differential equations of Maxwell's equations at initial and boundary conditions. The relevant load and boundry conditions are presented in Figure 4b.

In this study, numerical modeling of screw-connection terminal blocks was used in COMSOL Multiphysics program. The screw connection terminal dimensions used in the test were measured with a digital caliper and modeled according to these measurements. The model with screw connection terminals used for analysis is shown in Figure 5.

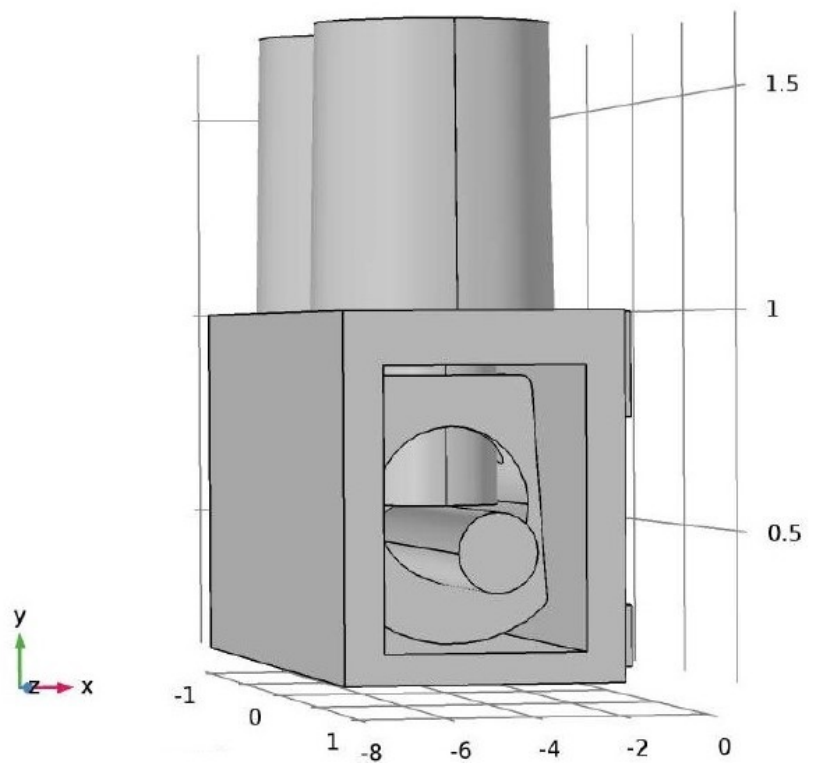

Figure 5 Installation of 1,5 $\mathrm{mm} 2$ copper cable to the model

Mesh settings of Comsol Multiphysics program and the screw connection terminal model were divided into small sections and the model's finite element network was formed. The wiring of the screw connection strips model consisting of 37174 finite elements is shown in Figure 6. In the study, the mesh structure was made by default in physics-controlled-mesh COMSOL program instead of user-controlled mesh.

\section{Analysis and Findings}

\subsection{Experimental Findings}

In the experimental set-up shown in Figure 1, different torque was applied to screw connections. The amount of change in diameter of the conductor depending on the torque applied to the screw is given in Figure 7. 
Tosun et al.

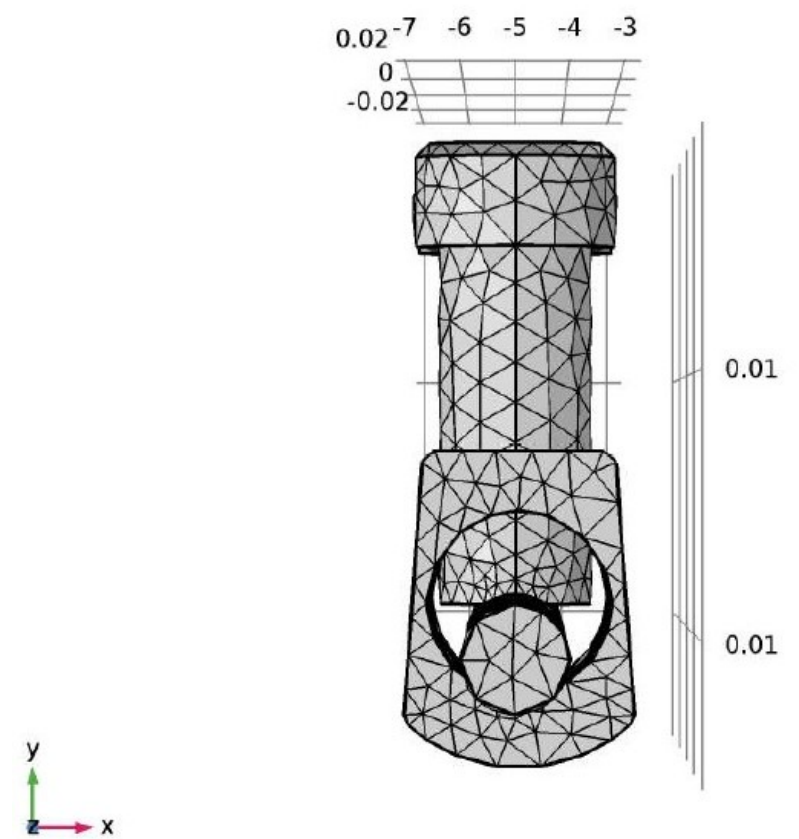

Figure 6 Mesh structure of model

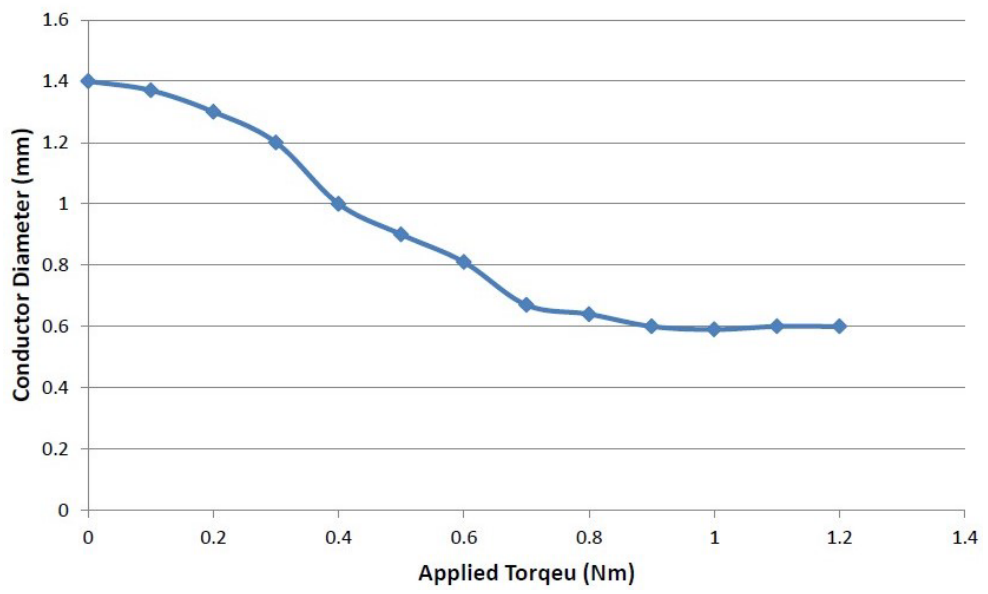

(a)

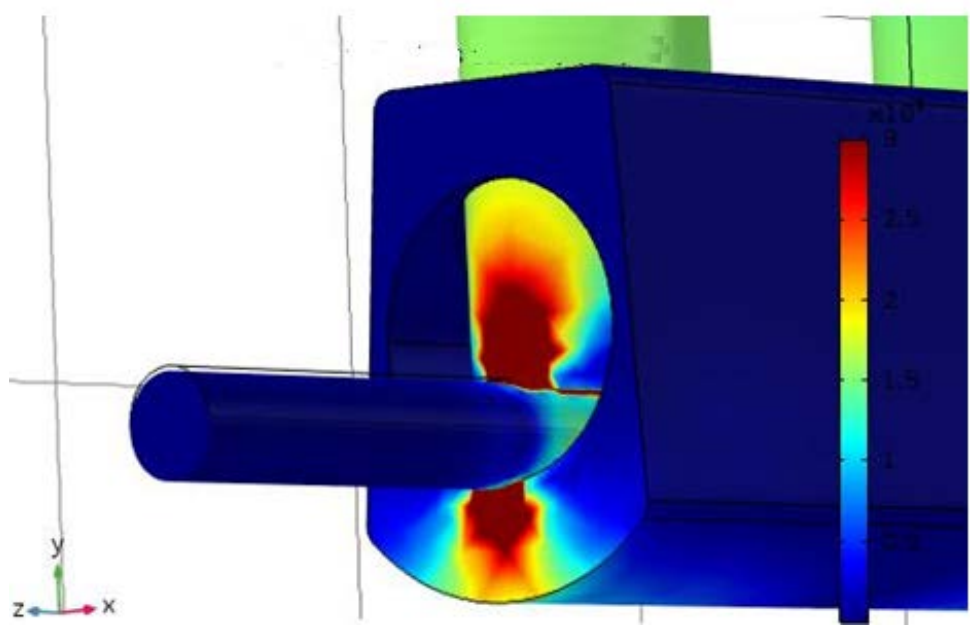

(b)

Figure 7 a) The amount of change in the conductor diameter depending on the applied torque b) Deformation of the cable on the comsol 
When constant 14 A current is applied to $1.5 \mathrm{~mm}^{2}$ cable conductor insert, which is applied to the screw connection terminal with $0.3 \mathrm{Nm}, 0.4 \mathrm{Nm}$ and $0.5 \mathrm{Nm}$ torque, respectively, temperature change values measured on the cable joint surface are shown graphically in Figure 8.

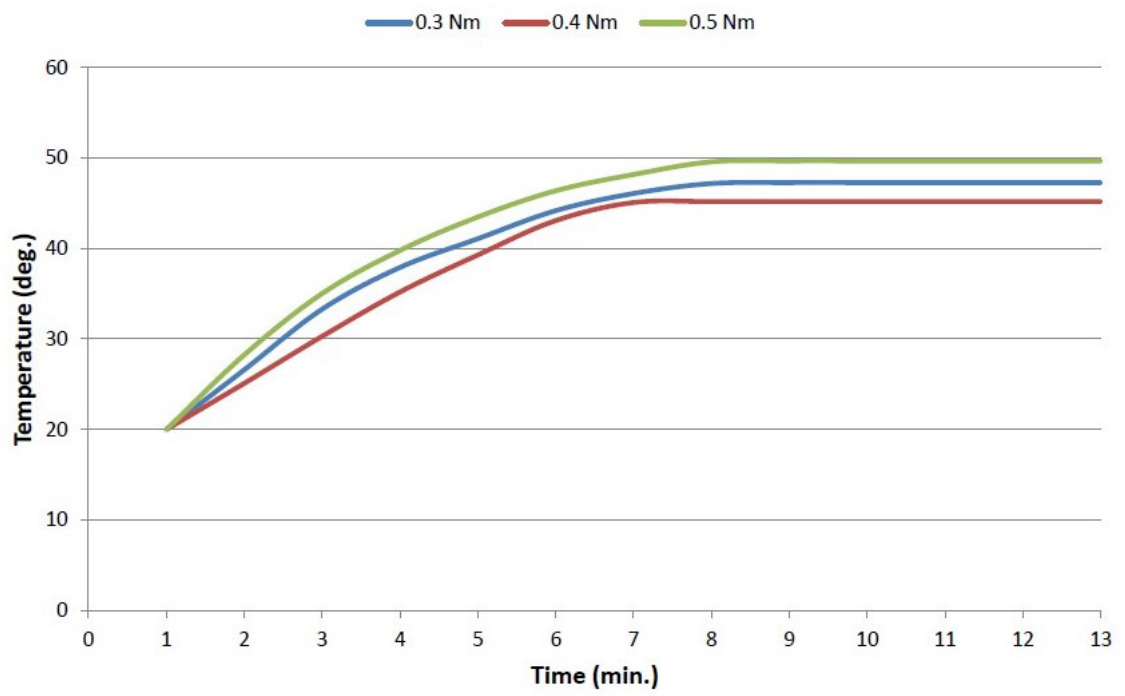

Figure $80.3 \mathrm{Nm}, 0.4 \mathrm{Nm}, 0.5 \mathrm{Nm}$ Torque values applied to the cable joint surface temperature change

\subsection{Mechanical Analysis and Findings}

In the structural mechanical analysis module of COMSOL software, solid mechanics solutions were realized depending on torque values applied to the screw with its solid mechanics. The terminal connection consisting of a contact with a non-prestressed screw was subjected to a load group consisting of an axial force and a torque. Effective stress values on the screw top surface and the cable joint is also shown in Figure 9 when the torque force of $0.3 \mathrm{Nm}$ is applied to the screw. The pressure change graph applied to the cable conductor contact surface of $0.3 \mathrm{Nm}$ torque force is shown in Figure 10a. Arc length is the pressure that occurs between the screw axis and the contact point of the cable conductor and its unit is meter as shown in Figure 10b.

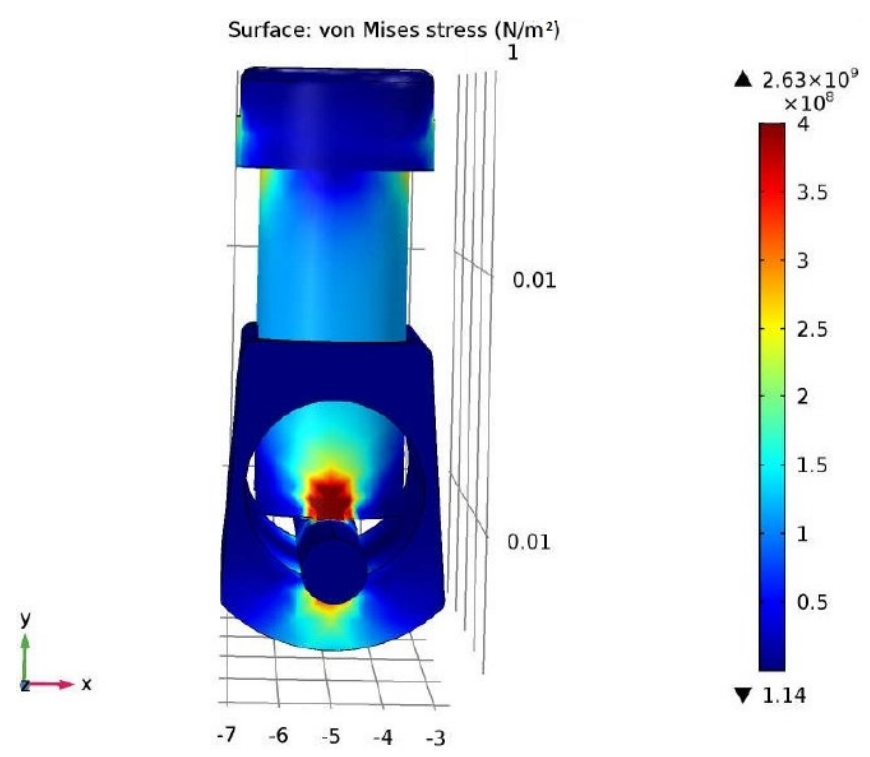

Figure 9 Effective stress at $0.3 \mathrm{Nm}$ torque applied screw 
Tosun et al.

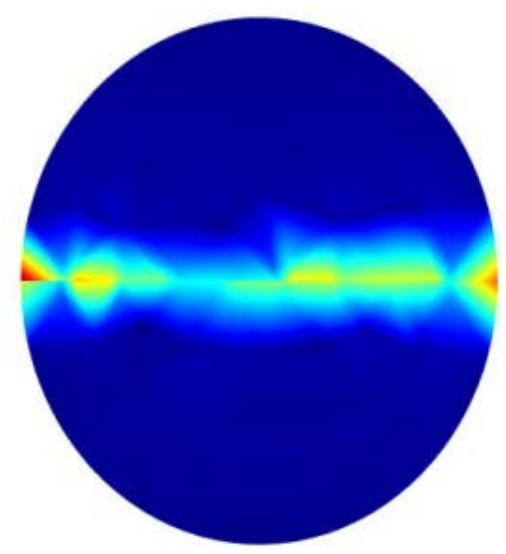

(a)

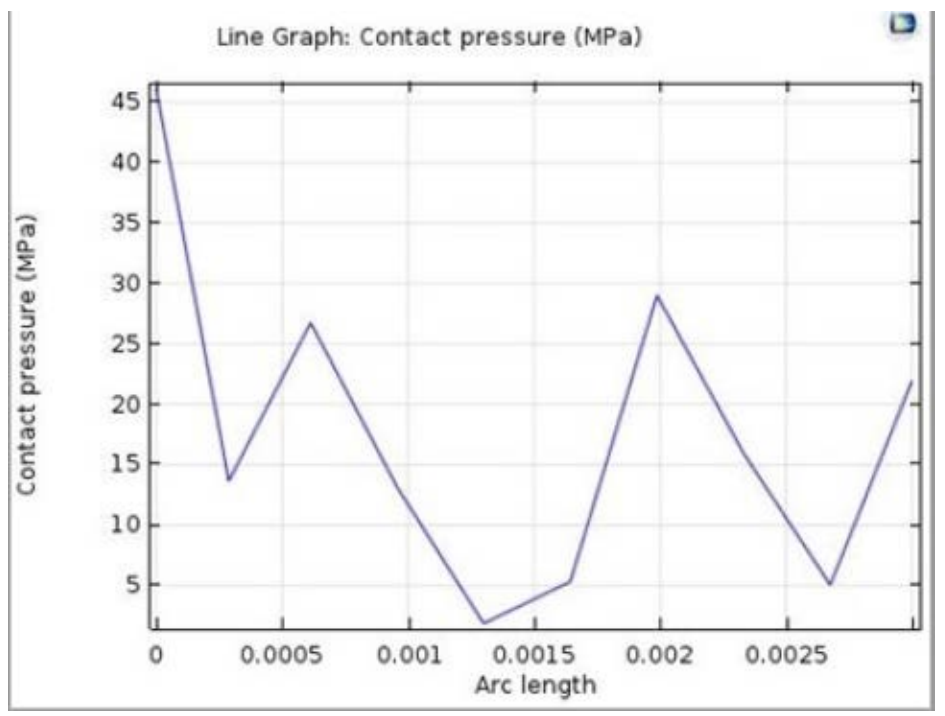

(b)

Figure 10 a) Pressure on screw axis and cable conductor contact surface, b) Change of contact pressure according to arc length (meter)

\subsection{Electrical Analysis and Findings}

Results of electrical potential analysis for the model generated by the finite element method are shown in Figure 11. Analysis of current densities for the model generated by the finite element method are shown in Figure 12 and Figure 13 The cable current density-temperature relationship of the contact zone is shown in Figure 14. The terminal strips upper zone current density-temperature change graph is shown in Figure 15. The higher the temperature, the higher the conductor's resistivity. Therefore, the current density, which increased to a certain degree, fell after a certain temperature value [29]. This situation can be seen in Figure 15. The change in current density along the conductive surface is given in Figure 16. This situation refers to the current change of the conductor on the upper part of the conductor, which is screwed with a screw on the surface of the conductor. It was observed that there was more current change in the junction region. 
Tosun et al.

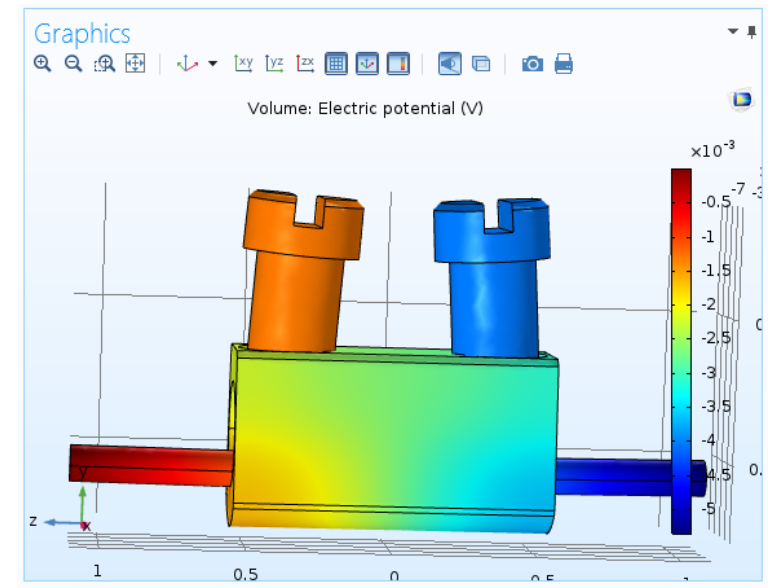

Figure 11 Electrical potential distribution for 14 A current value

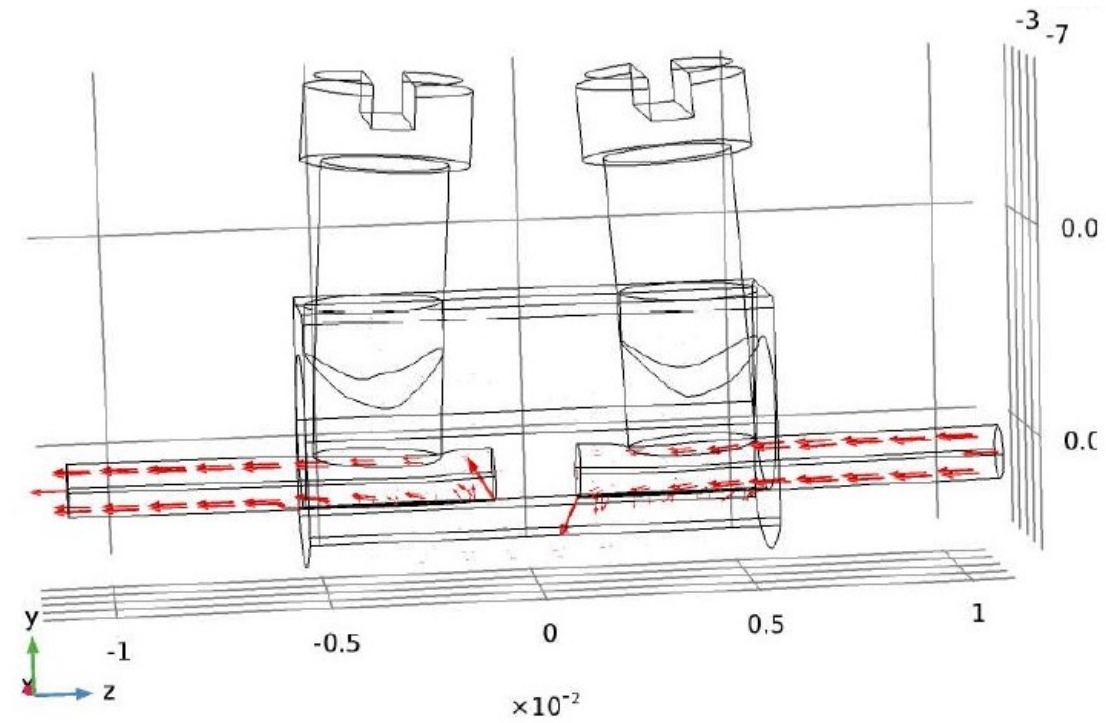

Figure 12 Distribution of current density $\left(\mathrm{A} / \mathrm{m}^{2}\right)$ on the model

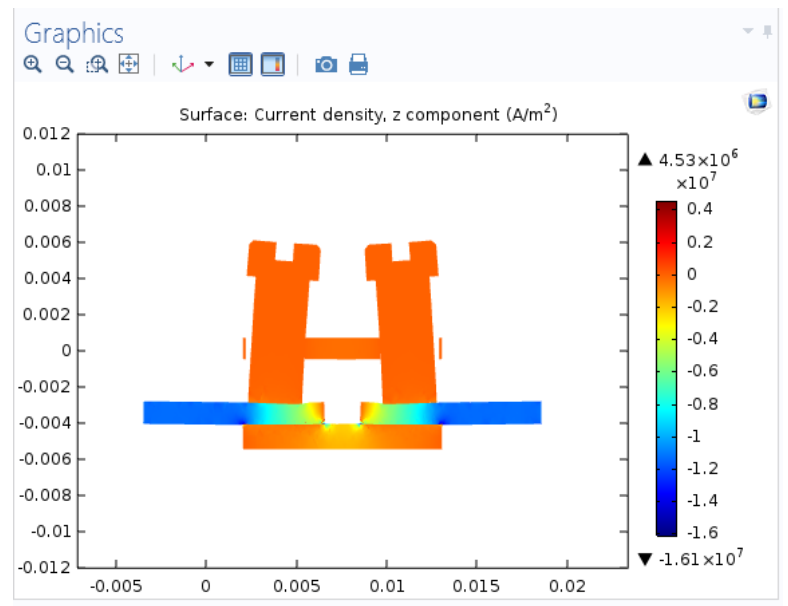

Figure 13 Analysis of the current density in the additional area of the model conductor 
Tosun et al.

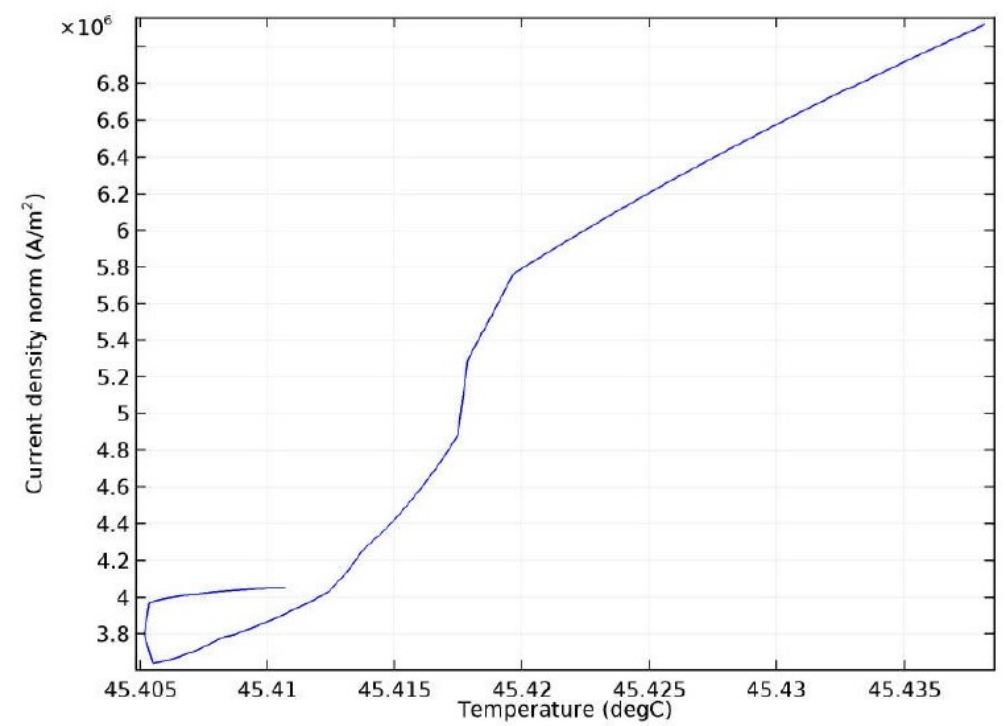

Figure 14 The relationship between the cable current density and temperature in the contact zone

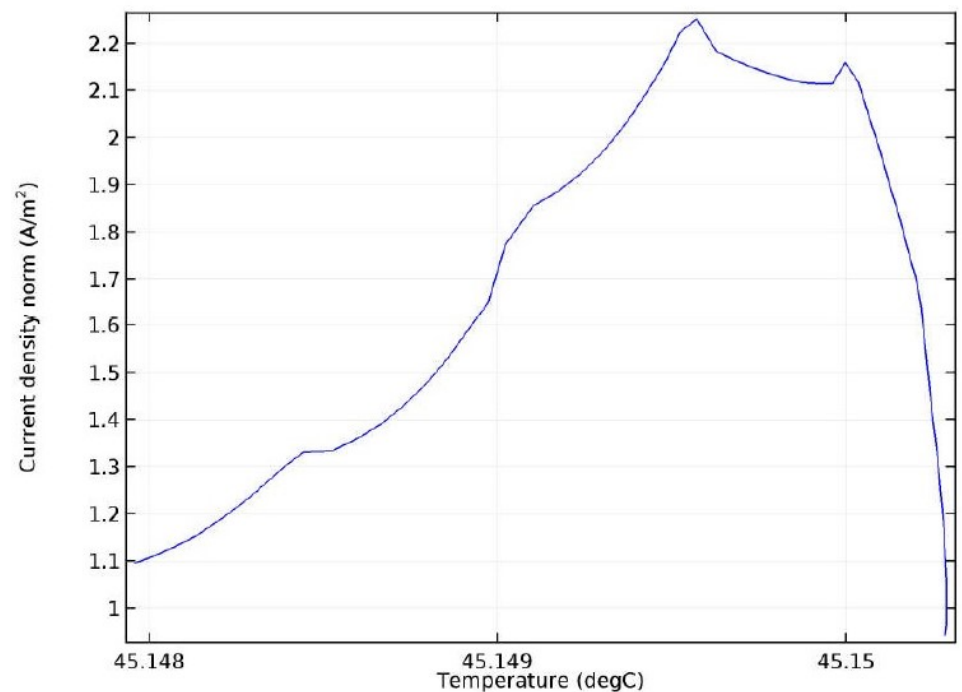

Figure 15 Screw top zone current density-temperature change graph

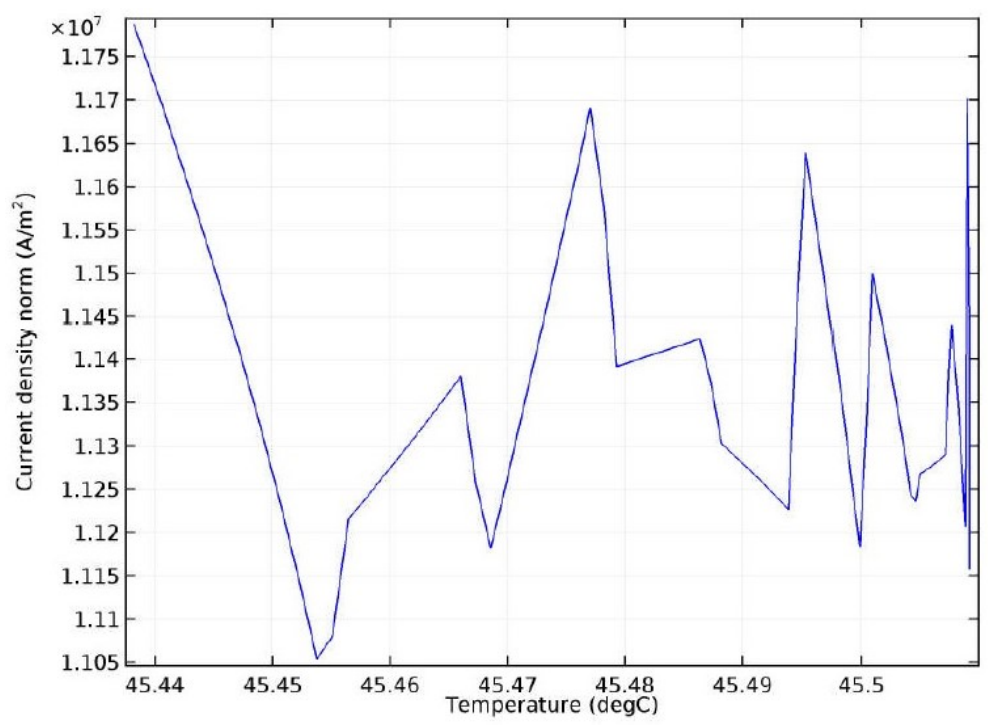

Figure 16 Change of current density along the conductor surface 


\subsection{Thermal Analysis and Findings}

In the thermal analysis, electrical current applied to the model and temperature changes in the contact surface were examined. The temperature changes of the contact surface, cable conductor and screw surfaces at the $0.3 \mathrm{Nm}, 0.4 \mathrm{Nm}$ and $0.5 \mathrm{Nm}$ torque forces applied to the screw connection terminal at 14 amp constant current are shown in Figure 17, Figure 18 and Figure 19, respectively.

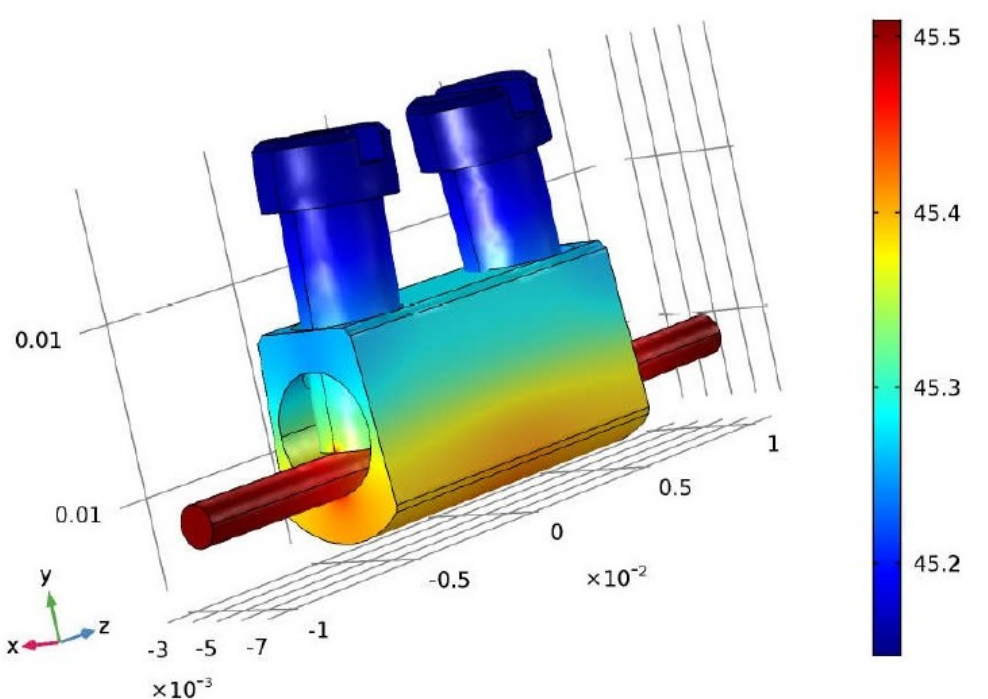

Figure 17 Temperature distribution for $0.3 \mathrm{Nm}$ and 14 A status

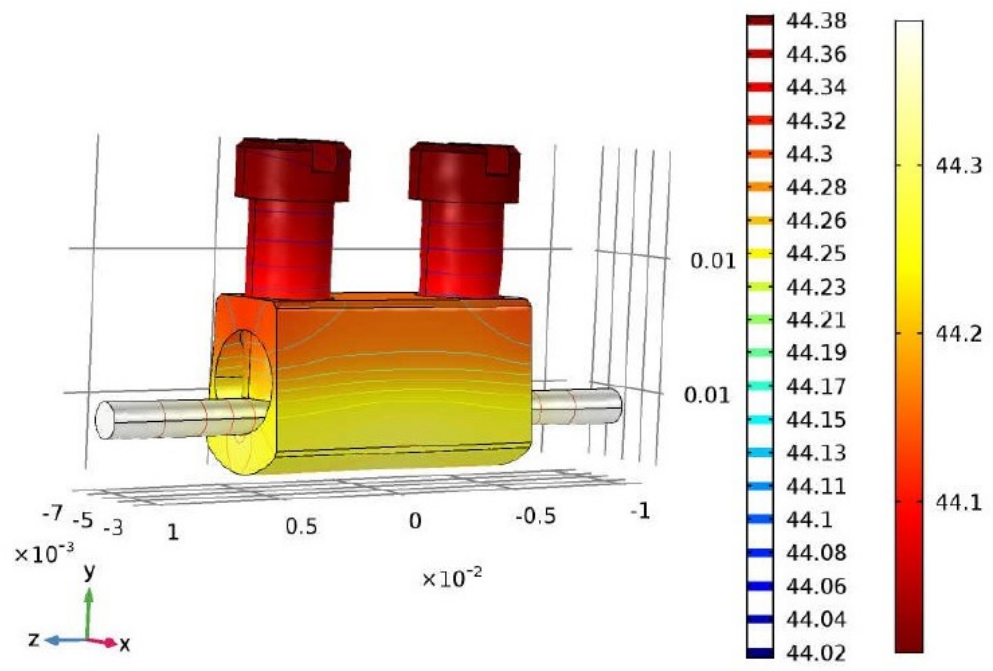

Figure 18 Temperature distribution for 0,4 $\mathrm{Nm}$ and 14 A status

\section{Discussion and Conclusions}

Unlike the electrical, thermal analysis studies performed in previous high voltage and current values $[6,7,11]$, electrical, thermal and mechanical analysis of the cable joints made with screw connection terminals produced for use in 220-volt voltage values have been performed in this study. When the results obtained from the numerical model and the experimental study are compared, the experimental values of temperature changes in cable joints made with screws tightened by applying the $0.3 \mathrm{Nm}, 0.4$ $\mathrm{Nm}, 0.5 \mathrm{Nm}$ force to copper conductor cable having $1.5 \mathrm{~mm}^{2}$ cross-sectional area were same with the 


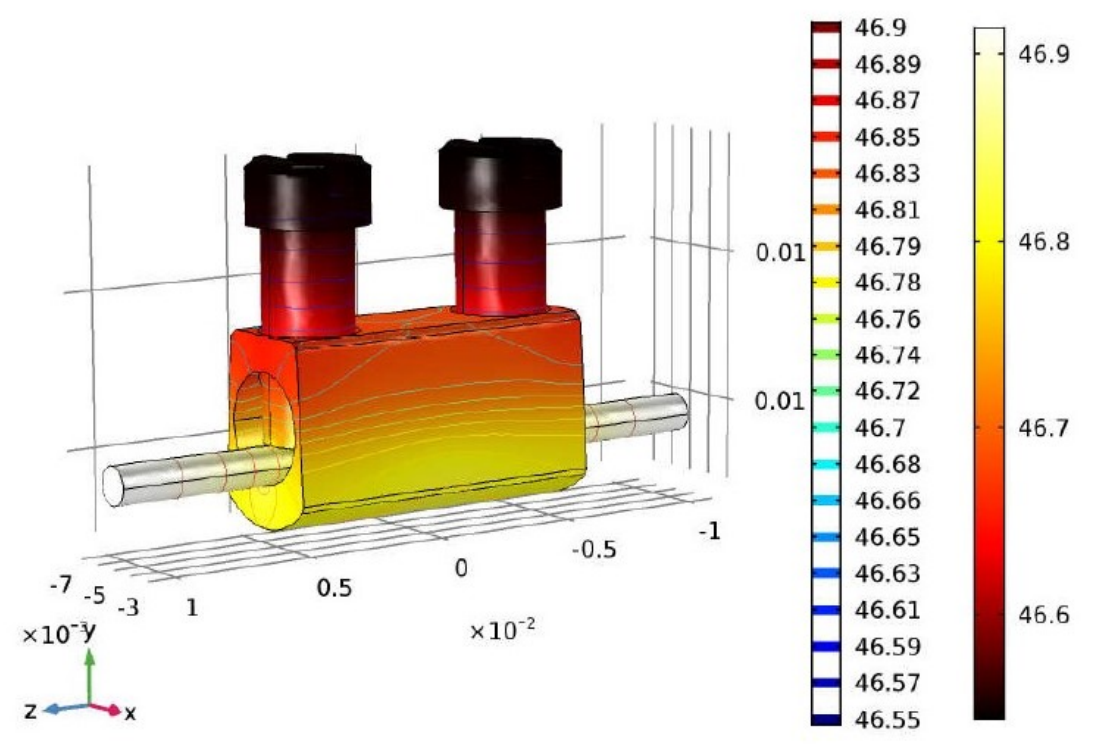

Figure 19 Temperature distribution for $0.5 \mathrm{Nm}$ and 14 A status

temperature values obtained in the numerical values. A similar situation was observed in electrical and mechanical analyses (Figure 8, Figure 17, Figure 18, Figure 19.)

In order to achieve the minimum cable section deformation and the minimum temperature increase with the numerical model, the optimum torque value applied to the screw were found as $0.4 \mathrm{Nm}$. In the connection made by applying the torque value of $0.3 \mathrm{Nm}$, the deformation was less but the contact surface was small and the temperature increase value was higher than the torque value of $0.4 \mathrm{Nm}$. In the connection made by applying the torque value of $0.5 \mathrm{Nm}$, the contact surface was large but since the amount of deformation in the cable was large, the temperature increase was the highest due to shrinkage of cable cross-section.

According to the results of the electrical potential analyses for the model generated by the Finite element method shown in Figure 11, the difference in the electrical potential from the point where voltage source is connected to soil decreased. In Figure17 and Figure18, it was found that the current was more intense in the conductive cross-sectional area than in the additional region. These results were similar to those results obtained by Ruan [6] and colleagues. Figure 12 shows that the current density increases on the outer surface of the cable. Shazly Jehan H. et al. [7] studied three-phase, XLPE-insulated $220 \mathrm{kV}, 340$ MVA, single-core copper power underground cable components and the highest values of temperature distributions in the surrounding environment occur with the highest temperature seen in the regions where the work occurs. Zhou et al. [11] reported that the electric field concentration of the electric field was higher than the cable joint but the electric field concentration was found tended to intensify in the small cavities in the inserts.

In our study, it was shown that small cavities in the cable contact points at the copper cable ends in the connection zone increased the current density concentration (Figure 13). In additional applications done without the use of a Torque Screwdriver, different deformations may occur in the conductor cable according to physical characteristics of apply personnel. In this study, the importance of the use of tools that can apply standard forces to the screw such as torque screwdriver has implementation of explanation, while cable joints are made. In this study, it was specified that electrical and thermal analyzes of cable joints in high voltage transmission lines are important and it shows that it is important to make these analyzes for inserts made at 220 Volt voltage values. In this study, a $1.5 \mathrm{~mm}^{2}$ crosssectional copper cable was also analyzed. Analyzes will also be carried out for copper cable joints with different cross sections, which are commonly used in residential electrical installations, in our future 
studies. In addition, same analysis can be performed for aluminum cables whose usage increases due toincrease in copper conductor prices.

\section{References}

[1] I. Vera and L. Langlois, ”Energy indicators for sustainable development,” Energy, vol. 32, pp. 875-882, 2007.

[2] M. Melikoglu, and M. Geothermal, "Energy in Turkey and around the World: A review of the literature and an analysis based on Turkey's Vision 2023 energy targets," Renewable and Sustainable Energy Reviews, vol. 76, pp. 485-492, 2017.

[3] A.K. Rajak, and S.D. Kore, "Experimental investigation of aluminium-copper wire crimping with electromagnetic process: Its advantages over conventional process”, Journal of Manufacturing Processes, vol. 26, pp. 57-66, 2017.

[4] S. Madhusoodhanan, K. Mainali, A.K. Tripathi, A. Kadavelugu, D. Patel, and S. Bhattacharya, "Power loss analysis of medium-voltage three-phase converters using 15-kV/40-A SiC NIGBT," IEEE Journal of Emerging and Selected Topics in Power Electronics, vol. 4, pp. $902-$ 917, 2016.

[5] İ. B. Kara, "2013-2017 yılları arasında artvin il merkezinde meydana gelen bina yangınlarının incelenmesi”, Doğ. Afet Çev. Dergisi, vol. 4, pp.105-114, 2018.

[6] J. Ruan, Q. Zhan, L. Tang, and K. Tang, "Real-time temperature estimation of three-core medium-voltage cable joint based on support vector regression,” Energies, vol. 11, no. 6, pp. 1405, 2018.

[7] J.H. Shazly, M.A. Mostafa, D.K. Ibrahim, and E.E.A. El Zahab, "Thermal analysis of highvoltage cables with several types of insulation for different configurations in the presence of harmonics,” IET Generation, Transmission Distribution, vol.11, pp.3439-3448, 2017.

[8] P.Y. Wang, H. Ma, G. Liu, Z.Z. Han, D.M. Guo, T. Xu, and L.Y. Kang, "Dynamic thermal analysis of high-voltage power cable insulation for cable dynamic thermal rating," IEEE Access, vol. 7, pp. 56095-56106, 2019.

[9] Q. Mei, W. Schoenmaker, S.H. Weng, H. Zhuang, C.K. Cheng, and Q. Chen, "An efficient transient electro-thermal simulation framework for power integrated circuits," IEEE Transactions on Computer-Aided Design of Integrated Circuits and Systems, vol. 35, pp. 832843, 2016.

[10] D. Xiao, C. Zhou, Q. Ma, J. Lei, and X. Du, "Wearable Intelligent Warning System for Approaching High-voltage Electrical Equipment," IEEE Transactions on Instrumentation and Measurement, vol. 69, no. 12, pp. 9389-9397, 2020.

[11] X. Zhou, J. Cao, S. Wang, Y. Jiang, T. Li, and Y. Zou, "Simulation of electric field around typical defects in 110kV XLPE power cable joints,” 2017 International Conference on Circuits, Devices and Systems (ICCDS), 2017. 
[12] B. Ren, C.T. Wu, and D. Lyu, "An h-adaptive meshfree-enriched finite element method based on convex approximations for the three-dimensional ductile crack propagation simulation," Computer Aided Geometric Design, vol. 76, pp. 101795, 2020.

[13] E.A. Rodrigues, O.L. Manzoli, L.A. Bitencourt, T.N. Bittencourt, and M. Sánchez, “An adaptive concurrent multiscale model for concrete based on coupling finite elements," Computer Methods in Applied Mechanics and Engineering, vol. 328, pp. 26-46, 2018.

[14] X. Song, V. Pickert, B. Ji, R.T. Naayagi, C. Wang, and Y. Yerasimou, "Questionnaire-Based Discussion of Finite Element Multiphysics Simulation Software in Power Electronics,” IEEE Transactions on Power Electronics, vol.18, pp. 7010-7020, 2018.

[15] G. Dagastine, "Numerical simulation-based topology optimization leads to better cooling of electronic components in toyota hybrid vehicles," Special Advertising Section to IEEE Spectrum: Multiphysics Simulation, 2012.

[16] M.F. Moulk1, and M. Khashab, “Haptic Servo System”, Dissertation, 2015.

[17] A. Hassani, M. Veyskarami, A. Al-Ajmi, and M. Masihi, "A modified method for predicting the stresses around producing boreholes in an isotropic in-situ stress field," International Journal of Rock Mechanics and Mining Sciences, vol. 96,pp. 85-93, 2017.

[18] Y.L. Hao, D.L. Gong, T. Li, H.L. Wang, J.M. Cairney, Y.D. Wang, and R. Yang, "Continuous and reversible atomic rearrangement in a multifunctional titanium alloy,” Materialia, vol. 2, pp. 1-8, 2018.

[19] R.A. Heindl, and L.E. Mong, "Young's Modulus of Elasticity, Strenght and Extensibility of Refractories in Tension," Part of Journal of Research of the National Bureau of Standards, vol. 17, pp.469-470, 1936.

[20] K. Kese, P.A. Olsson, and A. Holston, "Broitman, E. High temperature nanoindentation hardness and Young's modulus measurement in a neutron-irradiated fuel cladding material," Journal of Nuclear Materials, vol. 487, pp. 113-120, 2017.

[21] I. Zlotnikov, E. Zolotoyabko, and P. Fratzl, "Nano-scale modulus mapping of biological composite materials: Theory and practice.” Progress in Materials Science, vol. 87, pp. 292320, 2017.

[22] X. Zhao, C. Liu, C. Xu, G. Xu, Y. Zhang, S. Tan,, and Y. Han, "The effects of Ca2+ and Y3+ ions co-doping on reducing infrared emissivity of ceria at high temperature," Infrared Physics Technology, vol. 92, pp.454-458, 2018.

[23] S. Çevikalp, "Yüksek Basınçlı Sistemlerde Cıvata Üzerindeki Gerilmenin Burç Boyuna Göre Analizi ve Optimum Burç Boyunun Analiz Edilmesi,” Yüksek Lisans Tezi, İstanbul Teknik Üniversitesi, İstanbul, 2016.

[24] S.S. Rao, “The finite element method in engineering”, Butterworth-heinemann, 2017.

[25] M.N. Özişik, H.R. Orlande, M.J. Colaço, and R.M. Cotta, "Finite difference methods in heat 
transfer”, CRC press, 2017.

[26] D. Pepper and J. Heinrich, "The Finite Element Method: Basic Concepts and Applications with MATLAB,” MAPLE, and COMSOL, CRC Press, 2017.

[27] L. Monforte, M. Arroyo, J.M. Carbonell, and A. Gens, "Numerical simulation of undrained insertion problems in geotechnical engineering with the Particle Finite Element Method (PFEM),” Computers and Geotechnics vol. 82, pp. 144-156, 2017.

[28] L.A. Bitencourt, O.L. Manzoli, P.G. Prazeres, E.A. Rodrigues, and T.N. Bittencourt, “A coupling technique for non-matching finite element meshes," Computer Methods in Applied Mechanics and Engineering, vol. 290, pp. 19-44, 2015.

[29] A. Dalcalı, O. Çetin, C. Ocak, and F. Temurtaş, "Bir Elektromanyetik Fırlatıcı Bobininde Mermiye Etkiyen Kuvvetin Çok Katmanlı Sinir Ağı ile Kestirimi," Sakarya University Journal of Computer and Information Sciences, vol. 1, no. 3, pp. 1-10, 2018. 